\title{
Functions of Type II Pneumocyte-Derived Vascular Endothelial Growth Factor in Alveolar Structure, Acute Inflammation, and Vascular Permeability
}

\author{
Marco Mura, ${ }^{*}$ Matthew Binnie, ${ }^{\dagger \neq}$ Bing Han, ${ }^{*}$ \\ Chengjin $\mathrm{Li}^{\dagger}{ }^{\dagger}$ Cristiano F. Andrade, ${ }^{*}$ \\ Atsushi Shiozaki, ${ }^{*}$ Yu Zhang, ${ }^{*}$ \\ Napoleone Ferrara, ${ }^{\S}$ David Hwang, ${ }^{* \uparrow}$ \\ Thomas K. Waddell, ${ }^{* \|}$ Shaf Keshavjee, ${ }^{* \|}$ \\ and Mingyao $\mathrm{Liu}^{* \neq \|}$

\begin{abstract}
From the Latner Thoracic Surgery Research Laboratories, Toronto General Research Institute, University Health Network, and The Samuel Lunenfeld Research Institute, ${ }^{\dagger}$ Mount Sinai Hospital, Toronto, Ontario, Canada; the Departments of Medicine, ${ }^{\ddagger}$ Laboratory Medicine and Patbobiology, "ा and Surgery," University of Toronto, Toronto, Ontario, Canada; and the Department of Molecular Oncology, ${ }^{\S}$ Genentech Inc., South
\end{abstract} \\ San Francisco, California
}

Vascular endothelial growth factor-A (VEGF) is a potent regulator of vascular permeability, inflammatory response, and cell survival in the lung. To explore the functions of VEGF produced locally in type II pneumocytes, we generated mice with a conditional deletion of VEGF-A using Cre recombinase driven by the human surfactant protein C (SPC) promoter. In 7to 10-week-old VEGF-knockout (SPC-VEGF-KO) mice, lung histology and physiology were essentially normal, except for higher dynamic lung compliance and lower pulmonary vascular permeability. Emphysema was seen in 28- to 32-week-old animals. To investigate the role of type II pneumocyte-derived VEGF in acute lung injury, we challenged 7- to 10-week-old SPCVEGF-KO mice and their wild-type littermates with intestinal ischemia-reperfusion. Bronchoalveolar lavage fluid total cell count, pulmonary permeability, and lung injury score were significantly attenuated, and total lung VEGF levels were significantly lower in SPC-VEGF-KO mice compared with wild-type controls. In SPC-VEGF-KO mice, activated caspase 3-positive type II epithelial cells were increased after intestinal ischemia-reperfusion, even though there was no significant difference in the total number of cells positive for terminal deoxynucleotidyl transferase dUTP nick-end labeling. We conclude that VEGF in type II cells helps protect alveolar epithelial cells from caspase-dependent apoptosis. However, VEGF produced from type II cells may contribute to increased vascular permeability during acute lung injury. (Am J Pathol 2010, 176:1725-1734; DOI: 10.2353/ajpath.2010.090209)

Acute lung injury (ALI) and its severe form, acute respiratory distress syndrome (ARDS), are characterized by increased capillary permeability, leading to interstitial and alveolar edema, an influx of circulating inflammatory cells, and formation of hyaline membranes. However, the molecular mechanisms of ALI/ARDS are still largely unknown. Vascular endothelial growth factor-A (VEGF) is a potent regulator of vascular permeability, a key player in angiogenesis, and a survival factor for endothelial cells. ${ }^{1}$ The biological properties of VEGF are mainly mediated by VEGF receptor 2, also called Flk-1 (Fetal liver kinase 1), which is expressed on endothelial and epithelial cells. ${ }^{2,3}$ VEGF also induces monocyte activation and migration, which has been found to be mediated through VEGF receptor 1, also called Flt-1 (FMS-like tyrosine kinase 1). ${ }^{4}$ VEGF is considered to be both a vascular permeability factor and a pro-inflammatory cytokine. VEGF increases endothelial permeability via specific signal transduction pathways. ${ }^{5,6}$ Blocking VEGF has been shown to reduce tissue inflammation and damage in vivo. For example, VEGF-induced brain edema has some features that resemble stroke, ${ }^{7}$ and VEGF antagonism reduced edema formation and tissue damage in the brain after ischemia-reperfusion in mice. ${ }^{8}$ However, the role of VEGF in ALI/ARDS is controversial. ${ }^{9}$

Intrapulmonary overexpression of VEGF with an adenoviral vector resulted in high-permeability edema in

Supported by Canadian Institutes of Health Research grants MOP-13270 and MOP-42546.

M.M. and M.B. contributed equally to this work.

Accepted for publication December 16, 2009.

Address reprint requests to Dr. Mingyao Liu, Professor of Surgery, University of Toronto, Toronto General Hospital, Room TMDT 2-814, 101 College Street, M5G 1L7, Toronto, Ontario, Canada. E-mail: mingyao.liu@ utoronto.ca. 
murine lungs. ${ }^{10}$ Using an inducible transgenic mouse model, it was shown that VEGF overexpression in airway epithelium also induces pulmonary edema. ${ }^{11}$ Transfection of sFlt-1 gene attenuated bleomycin-induced pneumopathy in mice. ${ }^{12}$ Similarly, pretreatment of rats with adenovirus encoding soluble Flk-1 prevented ischemiareperfusion-induced lung injury. ${ }^{6}$ These results all suggest that VEGF signaling through its receptors may promote pulmonary permeability and inflammation. However, intriguingly, ischemia-reperfusion does not affect total VEGF protein levels in the lung. ${ }^{6}$ In addition, VEGF levels in the alveolar compartment of patients with ARDS are indistinguishable from those in patients with hydrostatic pulmonary edema. ${ }^{13}$ Lung epithelial lining fluid from ARDS patients actually contained lower levels of VEGF than that from at-risk subjects, and increased levels at Day 4 were associated with better recovery. ${ }^{14}$ Consistent with this finding, VEGF blockade has been shown to result in increased markers of oxidative stress, alveolar cell apoptosis and alveolar enlargement, ${ }^{15,16}$ suggesting a protective role for VEGF in the epithelial barrier. These interesting observations also suggest that the expression and function of VEGF may be regulated locally at sites of lung injury, without causing dramatic changes in overall lung VEGF levels.

VEGF is highly compartmentalized in the lung ${ }^{17}$ and is produced by multiple sources, such as epithelial and mesenchymal cells, myofibroblasts, and macrophages. ${ }^{1,18}$ However, type II alveolar epithelial cells are considered to be the main source of VEGF in the lung parenchyma, ${ }^{17}$ although the physiological role of VEGF from this source remains unclear. VEGF released by alveolar epithelial cells may act as an autocrine trophic factor for epithelial cells, ${ }^{19}$ and modulate functions of the adjacent vascular endothelium in a paracrine fashion. ${ }^{20}$ To investigate the roles of locally produced VEGF in the lung, we generated transgenic mice in which the expression of VEGF was selectively deleted in distal lung epithelial cells using a Cre recombinase system driven by the surfactant protein C (SPC)-promoter. While young transgenic mice showed a normal phenotype, older animals spontaneously developed typical features of initial emphysema. The severity of ALI, pulmonary permeability and inflammation, and the expression of cell death and stress markers were compared between transgenic young mice and their wild-type littermates after intestinal ischemia-reperfusion, a model of extrapulmonary ARDS. ${ }^{21}$

\section{Materials and Methods}

This study was approved by the Animal Use and Care Committee of the University Health Network. All animals received humane care in compliance with the Principles of Laboratory Animal Care formulated by the National Society for Medical Research and the Guide for the Care and Use of Laboratory Animals prepared by the Institute of Laboratory Animal Resources and published by the National Institutes of Health (NIH publication 0-309-05337-3, revised 1996), and the Guide for the Care and Use of Experimental Animals formulated by the Canadian Council on Animal Care.

\section{Cell-Specific Gene Targeting and Genotyping}

SPC-Cre transgenic mice were generated by cloning a cDNA encoding Cre recombinase and a nuclear localization signal downstream of the 3.7-kb human SPC promoter sequence, thus driving Cre expression in distal lung epithelium. This promoter confers gene expression throughout the lung epithelium during gestation and in a subset of type II pneumocytes postnatally. Transgene positive founders were identified by Southern blotting for Cre and tested for Cre activity by mating them to Z/EG reporter mice (ICR background), in which Cre-mediated excision of a stop codon leads to cell-specific expression of enhanced jellyfish green fluorescent protein (GFP). ${ }^{22,23}$ To confirm the specificity of gene targeting, dual transgenic SPC-Cre Z/EG offspring from one founder line were tested for GFP/prosurfactant protein C colocalization with immunofluorescent staining. The same SPC-Cre recombinase line (ICR background) was bred to floxed VEGF mice (ICR background) which have loxP sites inserted around the third exon (Figure 1A). Site-specific recombination between the two loxP sites of the VEGF gene results in a null VEGF allele. To generate homozygous floxed VEGF-

\section{A Tissue specific expression}

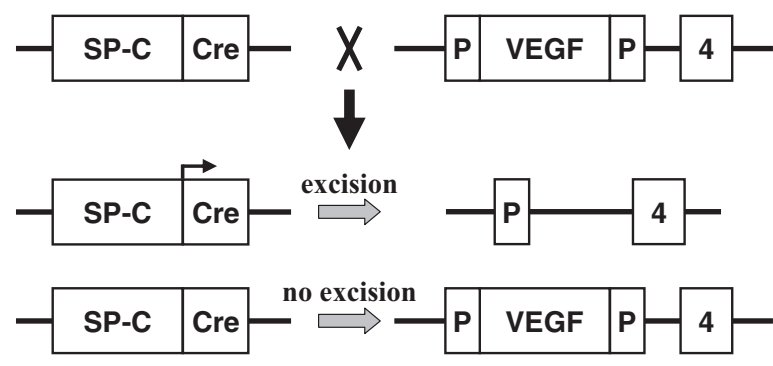

\section{B Cre PCR}

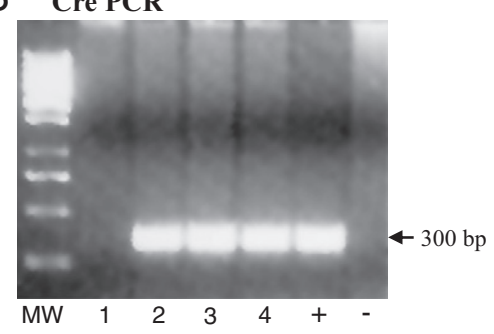

C VEGF PCR

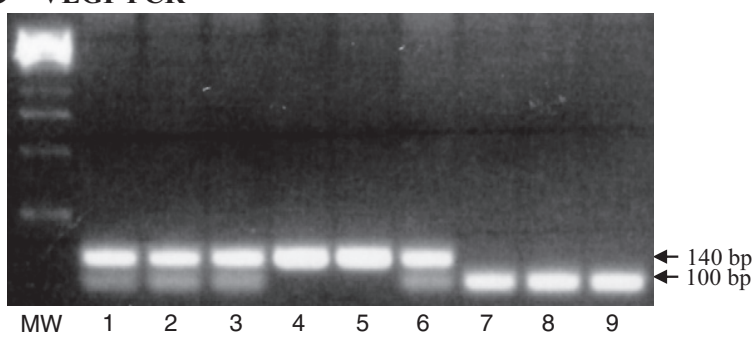

Figure 1. Cell-specific gene targeting and genotyping. A: Scheme to generate type II cell-specific VEGF knockout mice. B: Genomic DNA was isolated from mouse tails and used for genotypic analysis. The Cre recombinase transgene was identified as a 300 bp PCR product. +, positive control (DNA from known Cre positive mice); negative control (DNA from known Cre negative mice); MW, molecular weight markers. C: The floxed VEGF allele measures 140 bp by PCR analysis, whereas the wild-type allele measures $100 \mathrm{bp}$. Each lane represents one animal. 
Cre recombinase mice, mice carrying both a SPC-Cre transgene and one floxed VEGF allele were bred to homozygous floxed VEGF mice. The presence of the floxed VEGF gene was detected by PCR. ${ }^{24}$ Only homozygous knock-out animals (ie, Spc-Cre ${ }^{+/ 0}$ VEGF ${ }^{\text {lox/lox}}$ ) (SPC-VEGF $\mathrm{KO}$ ) and wild-type littermates were used. Recombination of the floxed allele deletes all VEGF isoforms (VEGF120, 164, and 188).

\section{Genotyping}

Genomic DNA was isolated from mouse tails and used for genotypic analysis. The presence of the floxed VEGF gene was detected by PCR using the oligonucleotide primers mUVEGF 419.F (5'-CCTGGCCCTCAAGTACACCTT-3') and mUVEGF 567.R (5'-TCCGTACGACGCATTTCTAG-3') (Sigma-Genosys, The Woodlands, TX), which generates a 140-bp fragment of the VEGF allele in the presence of the loxP-1 site and a 100-bp fragment in the wild-type allele.

\section{GFP-proSurfactant Protein C Double Immunofluorescent Staining}

To test for specific Cre recombinase expression in distal lung epithelium, colocalization of Cre-dependent GFP and the type II pneumocyte marker, surfactant protein C precursor protein (proSPC), was confirmed by double immunofluorescent staining. Lungs were chopped into fragments with a blade, fixed with $4 \%$ buffered formalin, processed, and embedded in paraffin; $5 \mu \mathrm{m}$ sections were deparaffinized and rehydrated. Sections were boiled in $0.01 \mathrm{~mol} / \mathrm{L} \mathrm{NaCitrate} \mathrm{[pH} \mathrm{6.0]} \mathrm{for} 10$ minutes and then cooled to room temperature. Sections were blocked with $5 \%$ goat serum in PBS for 1 hour at room temperature, incubated with primary antibody overnight at $4^{\circ} \mathrm{C}$, washed in PBS, then stained with secondary antibody for 1 hour at room temperature, washed in PBS, and mounted in Vectashield medium with 4,6-diamidino-2phenylindole (Vector labs, Burlingame CA). The antibodies used were rabbit anti-mouse proSPC (AB3786 1:500; Millipore, Billerica MA) and chicken anti-GFP (ab13970 1:1000; Abcam, Cambridge, MA) fluorescein isothiocyanate-conjugated anti-chicken $\lg$ Y (1:500) and Cy3-conjugated anti-rabbit IgG (1:500; Jackson Immunoresearch Laboratories, West Grove, PA) in the dark for 1 hour. After washing, slides were mounted with GVA mounting solution (Invitrogen, Carlsbad, CA). Thirty randomly chosen fields from two animals at $\times 200$ magnification were analyzed. The average number of GFP-positive cells was quantified as a percentage of total proSPC-positive cells counted. To determine the specificity of staining, the primary antibody was omitted from the staining protocol as a negative control. We also used lung tissue slide from wild-type animals, to show the lack of anti-GFP staining.

\section{Real-Time Reverse Transcription-PCR}

Quantitative real-time reverse transcriptase-PCR analysis of the RNA expression of VEGF was performed on RNA isolated from frozen lung tissues as previously described. ${ }^{25}$
Total RNA extraction was performed with the RNeasy kit (Qiagen, Mississauga, Ontario, Canada). Results are expressed as the ratio of VEGF and the housekeeping gene B2M expression levels. Primers were designed using the Primer Express 1.5 software (Applied Biosystems) and purchased from ACGT (Toronto, Ontario, Canada).

\section{Lung Morphometry}

For morphometric studies, the mean linear intercept was used as a measure of interalveolar wall distance, as described. ${ }^{26}$ The mean linear intercept was calculated for each sample based on 20 random fields observed at a magnification of $\times 400$ using a cross-line. Fields containing airways and blood vessels were excluded. The total number of alveolar intercepts encountered in each field was counted and the mean value for each animal (20 fields) was calculated. A lower mean linear intercept count represents more pronounced airspace enlargement.

\section{Physiological Analyses}

Seven- to ten-week-old male mice (weight $24.2 \pm 4.9 \mathrm{~g}$ in wild-type group, $26.7 \pm 5.3 \mathrm{~g}$ in SPC-VEGF KO group) were anesthetized with $5 \%$ isoflurane, intubated with a cannula $(1.0 \mathrm{~mm}$, Harvard Apparatus Canada, St. Laurent, Canada), and connected to a volume-controlled constant flow ventilator (Inspira Advanced Safety Ventilator, Harvard Apparatus). After intubation, anesthesia was continuously maintained with isoflurane and body temperature was maintained at $37^{\circ} \mathrm{C}$ by an immersion thermostat throughout baseline observation or IIR surgical procedure. The animals were ventilated with a tidal volume of $6 \mathrm{ml} / \mathrm{kg}$, inspiratory oxygen fraction 1.0, inspiratory/expiratory ratio $1: 2$, and a frequency of 140 breaths/min. Dynamic lung compliance was measured with an esophageal catheter. After 10 minutes of observation, either at baseline level or after 30 minutes of IIR, animals were sacrificed by exsanguination. Arterial blood gas analysis was performed in four 7- to 10week-old wild-type animals, three 7- to 10-weeks-old SPCVEGF KO animals, and four SPC-VEGF KO 28- to 32-weekold animals. HSE-USB acquisition system and Pulmodyn software (H. Sachs Elektronik, March-Hugstetten, Germany) were used for all pulmonary function measurements.

\section{Intestinal Ischemia-Reperfusion Model of ALI}

The IIR procedure was performed by occluding the superior mesenteric artery below the celiac trunk with an arterial microclamp for 30 minutes, as previously described $^{27,28}$; the reperfusion period was extended to 24 hours without mechanical ventilation or supplemental oxygen. Intestinal ischemia was confirmed by paleness of the jejunum and ileum. After 30 minutes the clamp was removed, $0.5 \mathrm{ml}$ of sterile saline at $37^{\circ} \mathrm{C}$ was injected into the peritoneal cavity and the skin was sutured. Anesthesia was terminated and animals were observed until a spontaneous breath appeared. Mechanical ventilation was then stopped and animals were let wean until a regular pattern of breathing was achieved. After 24 
hours, animals were resubmitted to anesthesia and laparotomy and sacrificed by exsanguination. For shamoperated animals, the same procedures were performed but the mesenteric artery was not clamped. Separate subgroups of lungs were 1) fixed for histological evaluation and immunohistochemistry studies; 2) snap-frozen in liquid nitrogen for protein or RNA analysis; 3) used for bronchoalveolar lavage (BAL) or Evans blue dye assay. Blood samples were collected after 24 hours of reperfusion by puncture of the aorta and centrifuged $(4000 \times \mathrm{g}$, 10 minutes). Plasma samples were stored at $-80^{\circ} \mathrm{C}$.

\section{Assessment of Lung Injury}

ALI was investigated by evaluating BAL cell counts, pulmonary vascular permeability, lung histology, and fibrin deposition with procedures previously described.27,28 Evans blue dye permeability assay was performed with the method described by Kaner et al. ${ }^{10}$ To assess fibrin deposition, fibrinogen immunohistochemistry was performed. ${ }^{29}$

The degree of lung injury was determined using the grading system developed by Ginsberg et al. ${ }^{30}$ The lung injury score comprises the assessment of four parameters: 1) alveolar hemorrhage, 2) vascular congestion, 3) infiltration or aggregation of neutrophils in the airspace or vessel wall, and 4) fibrin deposition in alveoli. The severity of each parameter was scored as 0 , absent; 1 , mild; 2, moderate; and 3, severe. The combined score of all four parameters was taken for each animal. ${ }^{30}$ Ten randomly chosen fields from each animal with approximately the same number of alveoli were analyzed by a pulmonary pathologist (D.H.), who was blinded to the group allocation.

\section{VEGF Expression}

VEGF gene expression was assessed by in situ hybridization using a probe kindly provided by Dr. Andras Nagy (University of Toronto, Canada). Lung tissues were prepared as previously described. ${ }^{31}$ In situ hybridization was conducted by a staff member of the core facility in our institute. For quantitative analysis, 10 optical fields of alveolar area from each animal (3 mice/group), not including major airways or vessels, were randomly chosen at $\times 1000$ magnification. The number of VEGF-positive cells as well as the total cell number of cell nuclei in the chosen fields were counted in a blinded fashion. The percentage of positivestained cells for each optical field was quantified as a percentage of total cells counted. VEGF levels in lung homogenates, BAL fluid and plasma were determined using an ELISA kit (R\&D Systems, Minneapolis, MN) ${ }^{28}$ that recognizes VEGF isoforms with either 120 or 164 amino acids. The lower detection limit was $31 \mathrm{pg} / \mathrm{ml}$. ELISA values in lung homogenates were standardized to total protein concentration.

\section{Immunofluorescent Staining}

Terminal transferase dUTP nick end labeling (TUNEL) staining, and TUNEL/activated caspase 3 double staining have been described. ${ }^{27}$ Activated caspase 3/Surfac- tant Protein B (SPB) double immunofluorescent staining was also performed. SPB was selected as a marker of Type II cells because SPC is known to be down-regulated in animal models of ALI. ${ }^{32}$ Clara cells are also SPB-positive, and therefore airways were excluded from the semiquantitative analysis. The staining was performed on $4 \mu \mathrm{m}$ lung slides. After deparaffinization and dehydration, antigen retrieval was performed with $10 \mu \mathrm{g} / \mathrm{ml}$ proteinase $\mathrm{K}$ in 10 $\mathrm{mmol} / \mathrm{L}$ Tris/HCl [pH 7.4 to 8] for 15 minutes. Slides were incubated with a rabbit anti-SPB polyclonal antibody (1:50 in PBS-1\% bovine serum albumin[BSA]) for 6 hours, washed with PBS, and then incubated with a Texas Red mouse anti-rabbit IgG (1:100 in PBS-1\% BSA; Jackson Immunoresearch) for 1 hour. Slides were next incubated with a goat polyclonal antibody against the activated (cleaved) form of caspase 3 (1:50 in PBS-1\% BSA) (Santa Cruz) overnight at $4^{\circ} \mathrm{C}$, washed with PBS and then incubated with a fluorescein isothiocyanate-conjugated donkey anti-goat IgG (1:500 in PBS-1\% BSA, Biotium, Hayward, CA) at room temperature for 1 hour. The nuclei were counterstained with Hoechst 33258 (1:5000, 10 minutes). All slides were subjected to identical exposure times. Nonimmune serum instead of primary antibody for caspase 3 was used for negative controls. Spleen sections (secondary follicles) were used as positive control. ${ }^{33}$ The average number of activated caspase 3-positive cells was quantified as a percentage of total Hoescht-positive cells counted; the average number of activated caspase 3-positive epithelial cells was also quantified as a percentage of total SPB-positive cells counted.

\section{Immunohistochemistry}

The detailed protocols published previously were followed. ${ }^{28}$ The primary antibodies used were anti-VEGF (1:200) (Santa Cruz Biotechnology, Santa Cruz, CA) and chicken anti-fibrinogen (1:400, GenWay Biotech San Diego, CA). Slides were then washed and incubated with biotinylated secondary antibody (1:600 in PBS-1\% BSA). Detection was done by Avidin Biotin Complex system by following the manufacturers' instructions (Vector Laboratories Inc, Burlingame, CA), using 3-3 Diaminobenzidine as chromogen; slides were counterstained with hematoxylin for 2 seconds. The primary antibody was omitted for negative controls. For fibrinogen staining, the secondary Ab was an alkaline phosphatase-conjugated anti-chicken $\lg Y$ (1: 100 in PBS-1\% BSA, 1 hour). Detection was done by Avidin Biotin Complex system (Vector Laboratories Inc., Burlingame, CA) with Vector Red alkaline phosphatase substrate kit as chromogen. Slides were counterstained with methyl green for 10 seconds.

\section{Western Blotting}

Antibodies for caspase-3 and horseradish peroxidaseconjugated donkey anti-goat secondary antibody were from Santa Cruz Biotechnology (Santa Cruz, CA). Cleaved caspase-3 antibody was from Cell Signaling Technology (Beverly, MA). Horseradish peroxidase-conjugated goat anti-rabbit secondary antibody was from Amersham Pharmacia Biotech (Piscataway, NJ). Immunoblotting experi- 
A proSPC and GFP staining
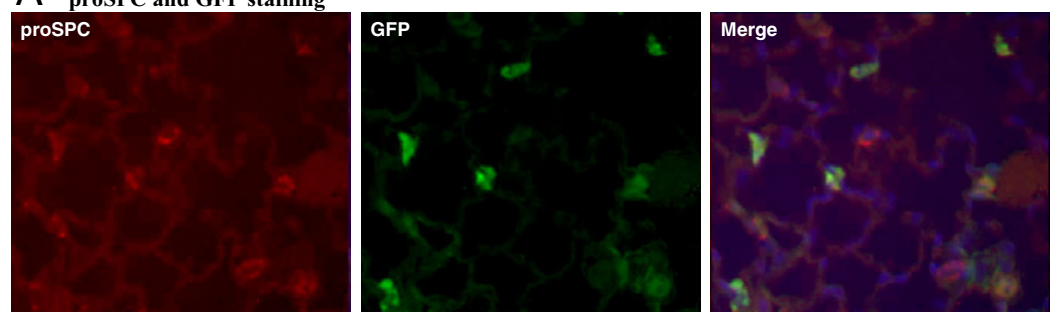

B VEGF in situ hybridization
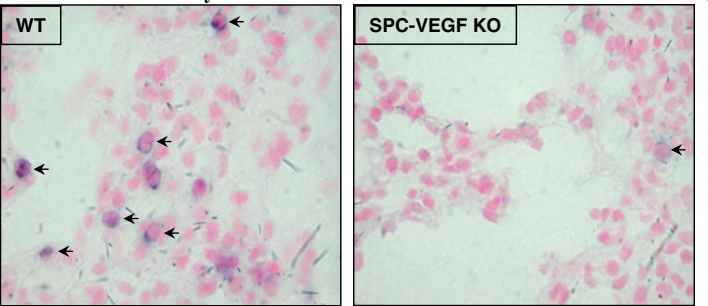

C VEGF gene expression in lung tissue

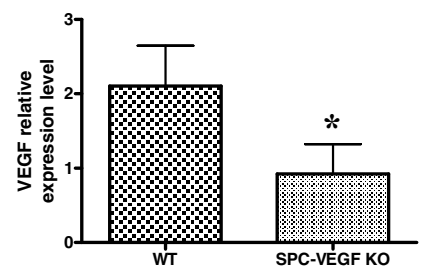

E VEGF-positive cells in lung sections
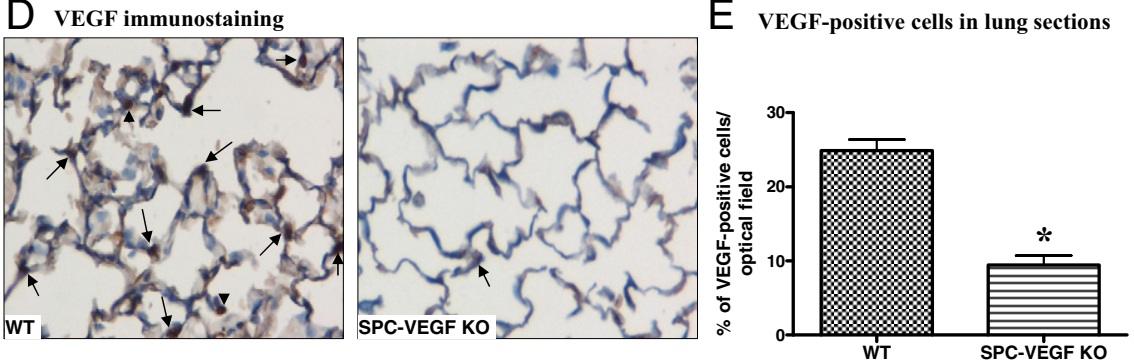

Figure 2. Selective deletion of VEGF in type II alveolar epithelial cells. A: Green fluorescent protein (GFP)-proSurfactant Protein C (proSPC) double staining, to determine the efficiency of SPC-promoter driven Cre-recombinase system in type II cells. GFP is stained with fluorescein isothiocyanate (green) and SPC with Cy3 (red). Nuclei are counterstained blue with 4,6-diamidino-2-phenylindole. Expression of GFP indicates cell-specific recombination and is seen in the majority of proSPC-positive Type II cells. Original magnification $\times 200$. B: In situ hybridization shows lack of VEGF mRNA expression in the alveolar wall of SPC-VEGF knockout (KO) animals. One VEGF positive cell in the KO group is to show the "leakiness" of the system. Arrows indicate VEGF-positive cells. Original magnification $\times 1000$. C: VEGF gene expression in lung tissue evaluated by quantitative Real-Time RT-PCR showing a significantly reduced expression in SPCVEGF-KO mice $(n=15)$ in comparison with wildtype animals $(n=12)$. ${ }^{*} P=0.0002$. D: VEGF immunostaining, showing much weaker staining in the alveolar walls in SPC-VEGF KO mice in comparison with wild-type littermates. Nuclei were counterstained with hematoxylin. Arrows indicate VEGF-positive type II cells, arrowheads indicate VEGF-positive macrophages. Original magnification $\times 1000$. E: Quantification of VEGFpositive cells, which was significantly lower in SPC-VEGF-KO mice $(n=3)$ in comparison with wild-type littermates $(n=3) .{ }^{*} P=0.001$. ments were performed according to standard procedures described previously. ${ }^{28}$

\section{Statistical Analysis}

All data are expressed as mean \pm SD. Distribution analysis for all variables were performed with the Kolmogorov-Smirnov test. For comparison of two separate groups either the unpaired $t$-test or the Mann-Whitney test was used, when indicated. For comparison of multiple groups, either one-way analysis of variance analysis followed by Tukey's post test or nonparametric Kruskal-Whallis test followed by Dunn's post test, when indicated, were used to determine significant differences between individual groups. $P$ values $<0.05$ are regarded as significant. The Prism 4 software package (GraphPad Software Inc., La Jolla, CA) was used for all statistical analyses.

\section{Results}

\section{Phenotype, VEGF Expression, and Physiology of SPC-VEGF-KO 7- to 10-Week-Old Mice}

To selectively knock out the expression of VEGF in type II cells we crossed SPC-Cre transgenic mice to mice homozygous for a floxed VEGF allele, then back-crossed SPC$\mathrm{Cre}^{+/ 0}$ VEGF ${ }^{\text {lox/wt }}$ offspring with VEGFlox/lox mice to generate SPC-Cre ${ }^{+/ 0} V$ EGF ${ }^{\text {lox/lox }}$ mutants. Mice were genotyped by PCR for Cre (Figure 1B) and VEGF (Figure 1C) alleles.
Wild-type and floxed VEGF alleles yield bands of different sizes. To determine the efficiency of SPC-Cre mediated recombination in vivo, transgene positive founders were mated with Z/EG reporter mice, in which Cre-mediated excision of a stop codon leads to cell type-specific expression of enhanced GFP. ${ }^{22,23}$ Expression of GFP, indicating SPCCre transgene expression, was observed in the small airways and air sacs during the perinatal period (data not shown). In adult mice, site-specific recombination was found in $71 \pm 8 \%$ of type II cells, as shown by GFP-proSPC double staining (Figure 2A). In SPC-VEGF-KO mice, reduced epithelial expression of VEGF in the alveolar space was demonstrated by in situ hybridization (Figure 2B). VEGF mRNA-positive cells (per optical field) were $10.8 \pm 1.4 \%$ in wild-type animals and $2.9 \pm 1.1 \%$ in SPC-VEGF-KO mice $(P=0.001)$. Quantitative real-time RT-PCR showed a significantly reduced expression in SPC-VEGF-KO mice in comparison with wild-type littermates $(P=0.0002)$ (Figure $2 \mathrm{C}$ ). At the protein level, wild-type animals were characterized by strong staining of bronchial epithelial cells and moderate to diffuse staining of vascular endothelial cells. Type II epithelial cells were intensely VEGF-positive. Alveolar macrophages were occasionally positive. In SPC-VEGF-KO animals, few type II alveolar epithelial cells were VEGF-positive, while alveolar macrophages showed positive VEGF staining; airway cell staining was preserved (Figure 2D). VEGF-positive cells (per optical field) were $24.9 \pm 2.5 \%$ in wild-type animals and $9.4 \pm$ $2.2 \%$ in SPC-VEGF-KO mice $(P=0.001)$ (Figure $2 \mathrm{E})$.

SPC-VEGF-KO mice (7- to 10-week-old) showed normal body weight. The lungs showed normal appearance and 


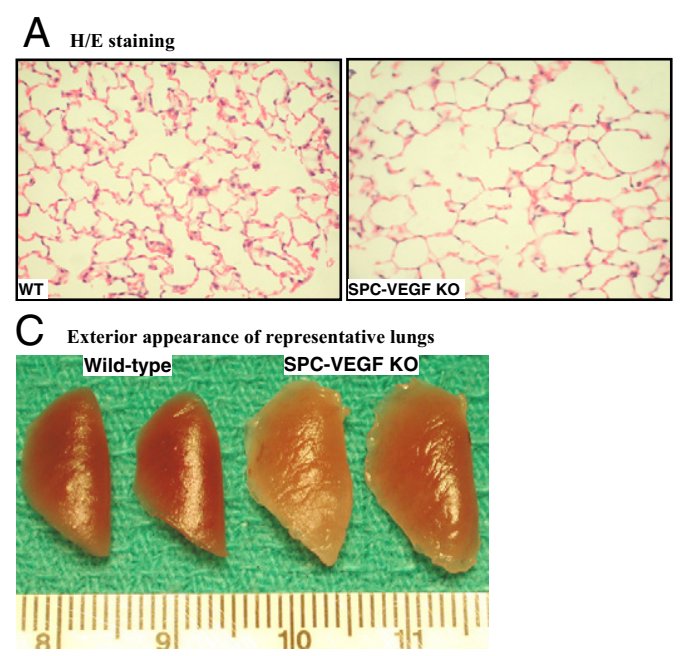

B Morphometric analysis

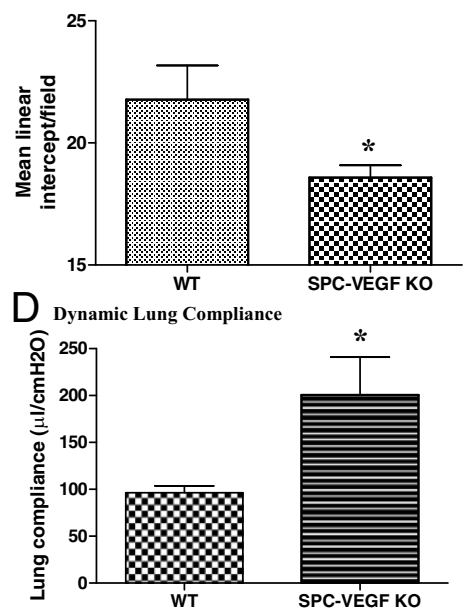

Figure 3. VEGF knockout (KO) in type II cells results in emphysema-like phenotype in 28- to 32-week-old SPC-VEGF KO mice. A: H\&E staining of lung tissues shows enlarged alveolar spaces in SPC-VEGF-KO mice. B: Morphometric analysis with mean linear intercept, which was significantly lower (meaning more pronounced airspace enlargement) in SPC-VEGF-KO mice $(n=6)$ in comparison with wild-type (WT) littermates $(n=10) .{ }^{*} P=0.0420$. C: Exterior appearance of representative lungs from SPCVEGF-KO mice and wild-type littermates at the age of 28 to 32 weeks. D: Dynamic lung compliance was significantly higher in SPC-VEGF-KO mice $(n=6)$ in comparison with wild-type littermates $(n=10) .{ }^{*} P=0.004$ histology. We performed physiological assessments of dynamic lung compliance, arterial blood gas analyses, and $\mathrm{BAL}$ for total and differential cell counts. No significant differences were found between SPC-VEGF-KO and wild-type mice in regard to blood gas analyses and BAL counts (data not shown). However, dynamic lung compliance was significantly higher $\left(123 \pm 42\right.$ vs. $96 \pm 24 \mu \mathrm{l} / \mathrm{cm} \mathrm{H}_{2} \mathrm{O} ; P=$ $0.015)$ and vascular permeability as measured by Evans blue dye assay was significantly lower (12.2 \pm 2.6 vs. $19.0 \pm 3.9$, \% of dose administered; $P=0.043)$ in SPCVEGF-KO mice compared with wild-type animals.

\section{The 28- to 32-Week-Old SPC-VEGF-KO Mice Develop Spontaneous Emphysema}

Morphological and physiological studies were also conducted on 28- to 32-week-old SPC-VEGF-KO animals and wild-type littermates. At histological analysis, air space enlargement was seen (Figure 3A), and increased lung volume was evident in some cases even on gross examination (Figure 3B). The morphometric analysis with the linear intercept method showed significant airspace enlargement (lower mean linear intercept), compatible with emphysema, in SPC-VEGF-KO animals in comparison with wild-type mice $(P=0.0420)$ (Figure $3 C)$. The dynamic lung compliance measurement confirmed higher values in SPC-VEGF-KO animals in comparison with wildtype littermates $(P=0.004)$ (Figure 3D).

\section{Acute Lung Injury Was Ameliorated in SPC-VEGF-KO 7- to 10-Week-Old Mice}

To investigate the role of VEGF in type II cells in the pathogenesis of $\mathrm{ALI}$, transgenic mice and their wild-type littermates were subjected to IIR. The 30-minute intestinal ischemia followed by reperfusion led to a 24 hours mortality of $25 \%$ in the wild-type group, $15.4 \%$ in the SPC-VEGF-KO group, and $0 \%$ in the Sham-WT group (Figure 4A). The severity of ALI was investigated by assessing cellular infiltration, pulmonary vascular permeability, histology, and fibrin deposition.
The BAL total cell count was significantly higher in wild-type mice after IIR, in comparison with the Sham-WT and SPC-VEGF-KO-IIR groups $(P<0.01)$ (Figure 4B). Pulmonary vascular permeability, assessed by Evans blue dye assay, was also significantly higher in the WTIIR in comparison with Sham-WT and SPC-VEGF-KO-IIR groups $(P<0.05)$ (Figure $4 \mathrm{C})$.

Lung architecture was preserved in Sham-WT animals, with minimal and occasional increases in cellularity. In the WT-IIR group, ALI was characterized by interstitial edema, alveolar hemorrhage, vascular congestion and infiltration of inflammatory mononuclear cells (Figure 5A). In comparison with wild-type mice, interstitial edema and cellular infiltration were strikingly reduced in the SPCVEGF-KO animals (Figure 5A). Fibrin staining was rare along alveolar septa and absent within alveolar spaces in Sham-WT and SPC-VEGF-KO animals, whereas dense deposits of fibrin were observed over inflammatory cells, in small vessels and along alveolar septa in wild-type mice after IIR (Figure 5B). The lung injury score, which is based on airspace hemorrhage, vascular congestion, fibrin in alveoli, and white blood cells in septa, was significantly lower in the SPC-VEGF-KO group in comparison with the WT-IIR group ( $P<0.05$ ) (Figure 4D).

In parallel with these observations of consistently reduced lung injury in transgenic animals subjected to IIR, VEGF intrapulmonary concentrations in the SPC-VEGF-KO group were significantly lower in comparison with Sham-WT and WT-IIR groups $(P<0.05)$ (Figure 4E). VEGF levels in BAL $(212 \pm 46 \mathrm{pg} / \mathrm{ml}$ in Sham-WT, $214 \pm 135 \mathrm{pg} / \mathrm{ml}$ in WT-IIR, $227 \pm 132 \mathrm{pg} / \mathrm{ml}$ in SPC-VEGF KO-IIR) and plasma $(15 \pm 12 \mathrm{pg} / \mathrm{ml}$ in Sham-WT, $8 \pm 6 \mathrm{pg} / \mathrm{ml}$ in WT-IIR, $6 \pm 2$ $\mathrm{pg} / \mathrm{ml}$ in SPC-VEGF KO-IIR) showed no significant differences among groups.

\section{More Epithelial Cell Death via Caspase-Dependent Mechanisms in SPC-VEGF-KO 7- to 10-Week-Old Mice during $A L I$}

Cell death is an important component in the development of $\mathrm{ALI} .^{34} \mathrm{IIR}$, in combination with mechanical ventilation 

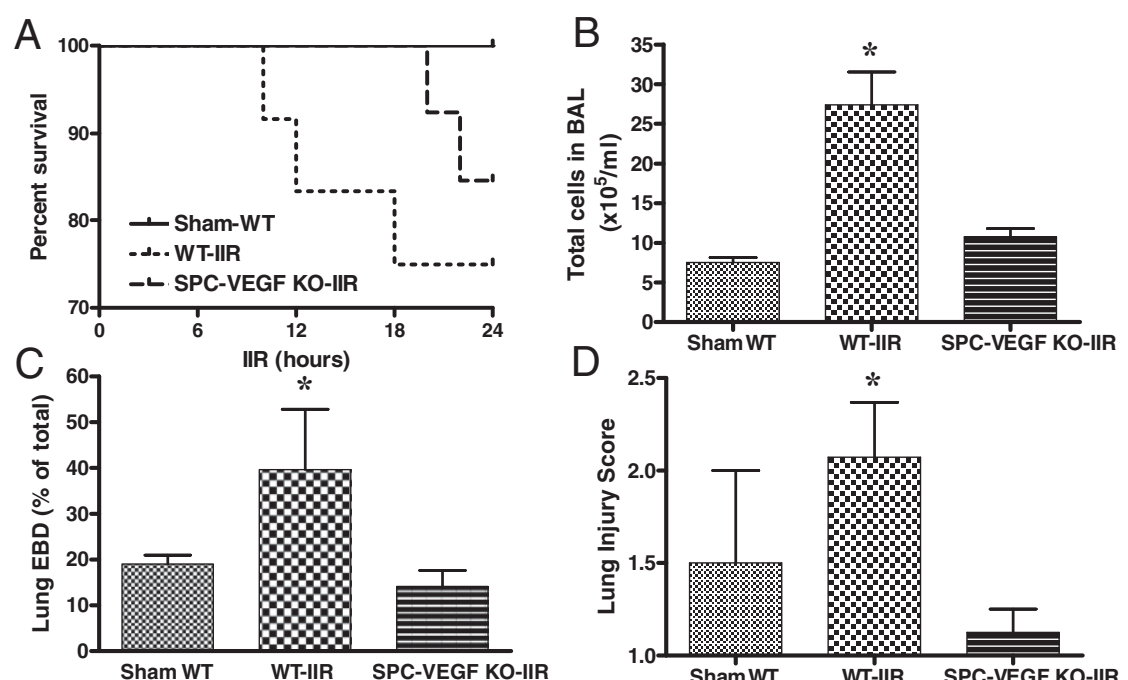

\begin{abstract}
Figure 4. Effects of VEGF knockout (KO) in type II cells on acute lung injury, VEGF intrapulmonary levels and alveolar epithelial apoptosis. A: Survival curves at 24 hours. B: BAL total cell count was significantly higher in WT-IIR group $(n=5)$ in comparison with Sham-WT $(n=3)$ and SPC-VEGF-KO-IIR mice $(n=6) .{ }^{*} P<0.01$. C: The Evans blue dye assay for pulmonary vascular permeability was significantly higher in WT-IIR group $(n=8)$ in comparison with Sham-WT $(n=4)$ and SPC-VEGF-KO-IIR mice $(n=6) .{ }^{*} P<0.05$. D: The lung injury score was significantly higher in the WT-IIR group $(n=7)$ in comparison with Sham-WT $(n=2)$ and SPCVEGF KO-IIR mice $(n=4) .{ }^{*} P<0.05$, WT-IIR versus SPC-VEGF-KO-IIR. E: VEGF concentration in lung homogenates, which was significantly lower in the SPC-VEGF-KO-IIR group $(n=9)$ in comparison with Sham-WT $(n=2)$ and WT-IIR mice $(n=7){ }^{*} P<0.05$. F: Percentage of activated caspase-3/SP-B double positive cells in the alveolar walls, which was significantly higher in the SPC-VEGF KO-IIR group $(n=4)$, in comparison with Sham-WT $(n=3)$ and WT-IIR $(n=5)$ groups. ${ }^{*} P<0.001$.
\end{abstract}
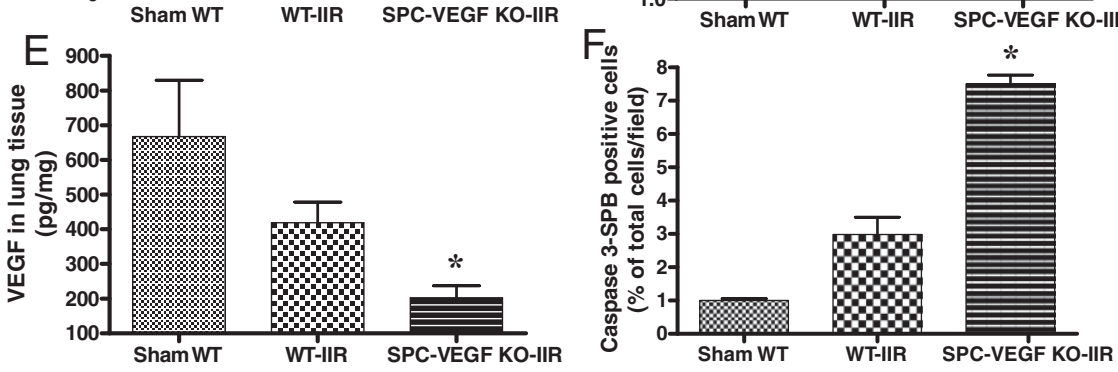

and high $\mathrm{FiO}_{2}$, induced oncotic cell death in the lung and other organs. ${ }^{27}$ To investigate the impact of selective deletion of VEGF in type II cells on cell death, we performed TUNEL staining, a marker of cell death. Massive TUNEL-positive signals were found only in animals dying within the first 24 hours of reperfusion, irrespective of groups. Using SPB as a marker of type II pneumocytes, we performed double staining of TUNEL and SPB. No difference was found between wild-type and SPCVEGF-KO mice after IIR (data not shown). We then performed double immunofluorescent staining for TUNEL and activated (cleaved) caspase 3, a marker of caspase- dependent apoptosis; no merging signals were found in the lungs from these dead animals (data not shown). Next, the percentage of activated caspase 3-positive cells in the alveolar wall was quantified and expressed as a percentage of the total number of cells per field; no significant difference was found, however there was a trend toward higher levels in SPC-VEGF KO mice compared with wild-type littermates after IIR $(P=0.058)$. We then used double immunofluorescent staining for activated caspase 3 and SPB. Epithelial cells undergoing caspase-dependent cell death (activated caspase 3-SPB double positive cells) were significantly higher in SPC-

\section{A H/E staining}

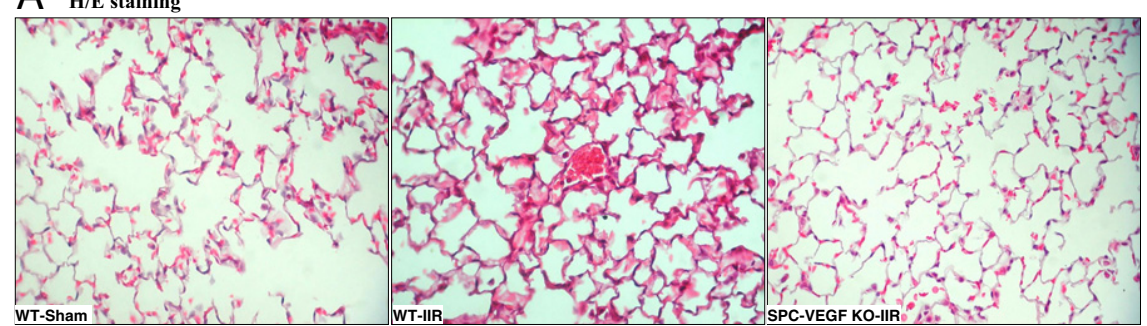

\section{B Fibrin immunostaining}

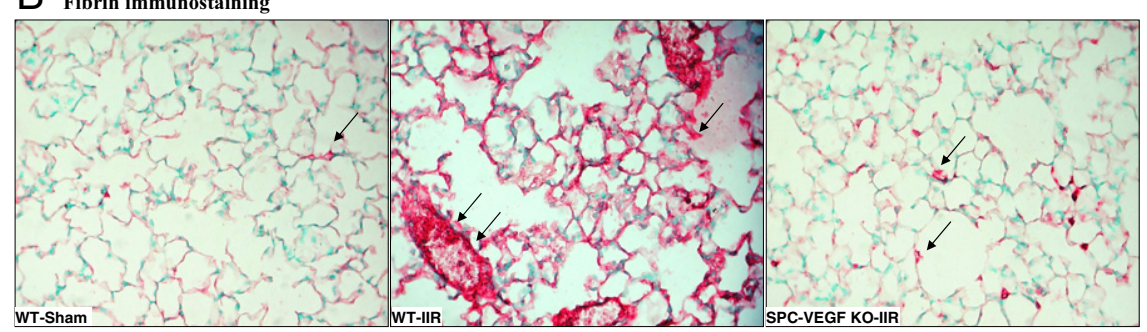

Figure 5. VEGF knockout (KO) in type II cells ameliorates the histological features of acute lung injury A: H\&E staining of lung tissues shows increased cellularity, interstitial edema, and vascular congestion in wild-type mice after IIR, in comparison with Sham-operated animals In SPC-VEGF-KO mice subjected to IIR these lung injury features were reduced. B: Extensive fibrin deposition (deep pink aggregates, examples are indicated with arrows) was observed in the lungs of wild-type mice after IIR, which was much lower in Sham-WT and SPC-VEGF-KO-IIR mice. Nuclei were counterstained with methyl green. $\mathbf{A}$ and $\mathbf{B}$ : original magnification, $\times 400$. 
A Activated (Cleaved) Caspase 3 (red)/SP-B (green) immunofluoerescence

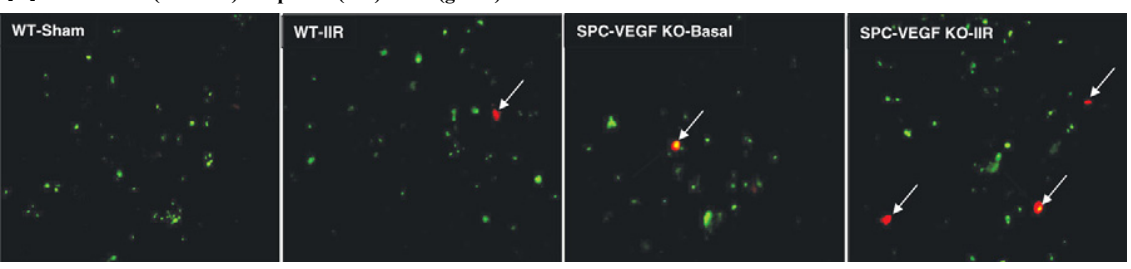

B Caspase 3 Western Blot

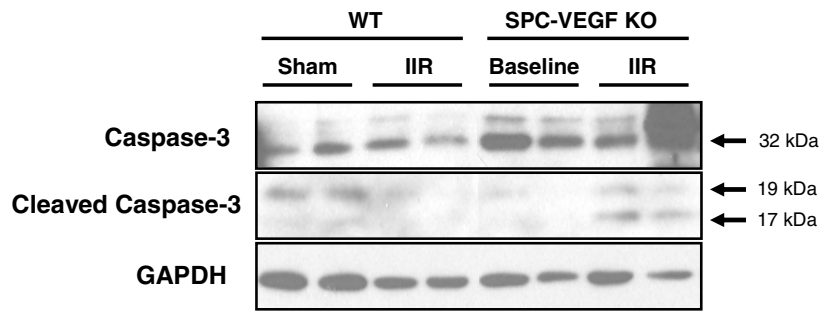

VEGF-KO animals at baseline compared with Sham-WT mice $(5.3 \pm 3.3 \%$ vs. $1.0 \pm 0.1 \%, P<0.05)$ (Figure 6A). After IIR, the percentage of caspase 3-SPB double positive cells was further increased in SPC-VEGF-KO animals, and significantly higher when compared with WTIIR littermates $(P<0.001)$ (Figures 6A and 4F). Western blotting of homogenized lung tissues confirmed the increase of total caspase 3 and activated (cleaved) caspase 3 in the SPC-VEGF-KO animals, especially after IIR (Figure 6B).

\section{Discussion}

In the present study, using a conditional targeting strategy, we provide evidence that VEGF produced in type II alveolar epithelial cells plays an important role in maintaining alveolar structure in adults and in mediating ALI by regulating pulmonary permeability and inflammation.

One challenge in determining the role of VEGF in the lung is that VEGF can be produced by many cell types with different capacities. Different cellular sources of soluble VEGF may compensate for one another during lung development and in acute inflammatory response and other diseases. This may explain why the expression of VEGF in ALI varies among animal models ${ }^{35,36}$ and in patients at different clinical stages. ${ }^{13,14,17,37,38}$ Overexpression of VEGF or inhibition of VEGF with chemical inhibitors or soluble decoy receptors can show the overall role of VEGF, but cannot dissect the contribution of VEGF from different cell types. Type II cells produce VEGF in vitro $^{39}$ and are a source of expression of VEGF protein ${ }^{40}$ and $m R N A^{41}$ in the adult lung. To determine the functions of VEGF produced by these cells, we selectively deleted the VEGF gene in distal lung epithelium using Cre recombinase driven by SPC promoter. The efficiency of conditional knock-outs is variable and depends on the promoter activity. Using Z/EG reporter mice we determined that this system is effective in about $70 \%$ of type II cells (based on anti-SPC staining as a denominator). Further confirming the reliability of VEGF deletion in type II cells, the overall expression of VEGF, both at the RNA and
Figure 6. VEGF knockout (KO) in type II cells increases caspase-dependent apoptosis in the alveolar wall in 7- to 10-week-old mice. A: Double immunofluorescent staining for activated (cleaved) caspase 3 (red) and Surfactant Protein B (SP-B) (green), showing increased number of activated caspase 3-positive type II cells (arrows) in SPCVEGF-KO animals in both baseline and IIR conditions, in comparison with their wild-type littermates. Original magnification, $\times 1000$. B: Western blotting showing total caspase 3 and cleaved (activated) caspase 3 in lung tissue lysates from different groups of animals. protein level, was consistently reduced in SPC-VEGF KO mice as demonstrated by qRT-PCR, quantification of in situ hybridization, and immunohistochemistry.

It has been shown that heterozygous null VEGF mice die at approximately embryonic day 10.5 from defective vasculature, ${ }^{42}$ and mice with heterozygous deletion of VEGF in kidney podocytes develop renal disease by 2.5 weeks of age. ${ }^{24}$ In the present study, conditional targeting of VEGF in type II cells did not significantly affect lung development from embryonic to young adult stages. VEGF produced from other cell types ${ }^{18,20}$ may compensate for deficiency of VEGF in distal lung epithelium. However, using more sensitive measures we found increased dynamic lung compliance and lower vascular permeability in young adult mice even though other physiological parameters appear to be normal. Indeed, a more complete deletion of lung epithelial VEGF does result in a disruption of lung development. ${ }^{43}$

In relatively older mice, emphysema-like pathologica findings were revealed. VEGF receptor blockade ${ }^{44}$ or adenoviral vector mediated specific VEGF inactivation in type $\|$ cells $^{16}$ also leads to emphysema phenotypes. These results indicate that VEGF produced in type II cells is critical to maintain the alveolar structures, especially in relatively older adults. It is noteworthy that VEGF overexpression also leads to changes in pulmonary function ${ }^{45}$ and air space enlargement, ${ }^{46}$ suggesting that a balanced expression in the complex VEGF system is essential for the maintenance of lung homeostasis. Multiple factors determine the responses of lung tissue to VEGF, including dose and type of VEGF, the presence of other confounding factors, developmental stage of the lung, type and duration of tissue injury, and others. Therefore, caution should be exercised in extrapolating data from animal studies to other lung injury models and human diseases.

In the present study, we demonstrated that selective deletion of VEGF in type II cells reduced IIR-induced ALI. VEGF is a well-known vascular permeability factor. ${ }^{1,9,47}$ VEGF can reduce transendothelial electrical resistance, induce endothelial migration ${ }^{5}$ as well as phosphorylation 
of VE-cadherin and E-cadherin, and alter the actin stress fibers in pulmonary endothelial cells. ${ }^{6}$ Using a ventilated pulmonary ischemia model in isolated ferret lungs, it has been shown that pulmonary vascular barrier dysfunction is associated with a rapid increase in VEGF expression. ${ }^{48}$ Similar results have been reported in a unilateral lung ischemia model. ${ }^{36}$ In the present study, 24 hours after IIR, transgenic mice showed significantly lower pulmonary vascular permeability and attenuated interstitial edema. Moreover, the chemotactic activity of VEGF may contribute to monocyte activation and migration. ${ }^{9}$ Lack of type II epithelial cell-derived VEGF may reduce the recruitment of inflammatory cells into the lung. Our results strongly support the hypothesis that VEGF locally produced in the distal lung epithelial cells is important for the pathogenesis of ALI/ARDS.

Despite improvement in ALI, some mortality was observed even in SPC-VEGF KO animals. This can be explained by our previous observation of severe decrease of blood arterial pressure, systemic inflammation, and multiorgan dysfunction and cell death occurring in the IIR model in mice. ${ }^{28}$

Cell death is one of the underlying mechanisms of ALI. ${ }^{34}$ Although apoptosis is involved in ALI, it is not the only form of cell death. Other types of cell death, such as caspase-independent cell death, oncosis, autophagy and necrosis are more pro-inflammatory. ${ }^{34}$ We previously demonstrated that the prevalent pattern of cell death in IIR-induced ALI at 4 hours is oncosis. ${ }^{27}$ In the present study, we found that the number of caspase 3/SPB double positive cells was increased in the SPC-VEGF-KO mice after IIR. These results suggest that the lack of constitutive VEGF signaling may induce type II cells to undergo caspase-dependent cell death, which may also contribute to the increased dynamic lung compliance seen in these animals. It is well-known that VEGF is an important survival factor for endothelial cells. ${ }^{49}$ Recently, we $^{28}$ and others ${ }^{19}$ have found that VEGF is also important for alveolar epithelial cells to survive. Knock-down of VEGF expression with short interfering RNA resulted in death of human lung epithelial cells in culture, and decreased VEGF in lung tissue was associated with increased death of type II cells in vivo. ${ }^{28}$ On the other hand, the total number of TUNEL-positive, as well as TUNEL/SPB-positive cells, showed no significant difference between wild-type and SPC-VEGF-KO mice after IIR. It has been shown that TUNEL staining may reflect DNA injury, apoptotic ${ }^{50}$ or necrotic cell death. ${ }^{51,52}$ Since the total TUNEL staining and TUNEL+/SPB + cells did not change significantly, the total amount of type II cell death may be similar in both wild-type and SPC-VEGF KO mice during ALI, but the mechanisms of type II cell death were switched toward caspase 3-dependent apoptosis in SPC-VEGF KO animals.

In conclusion, we provided evidence that VEGF produced by type II cells is important to maintain the alveolar structure, especially in adulthood. Results from targeted blockade of VEGF in type II cells point to a complex role for VEGF in acute lung injury as an important factor contributing to the acute inflammatory response and pulmonary edema on the one hand, and as a protective factor for the alveolar epithelial barrier, on the other.
Therefore, caution should be taken when considering VEGF as a therapeutic target for ALI/ARDS.

\section{Acknowledgments}

We gratefully acknowledge Dr. Susan E. Quaggin (Department of Medicine, University of Toronto) for her continuous support and insightful advice on this research project. We also thank Dr. Jing Xu, Dr. Huadong Zhu, and Zhihong Yun (University Health Network, Toronto, Canada) and Dr. Vera Eremina (The Samuel Lunenfeld Research Institute, Mount Sinai Hospital, Toronto, Canada) for their technical assistance.

\section{References}

1. Ferrara N, Gerber HP, LeCouter J: The biology of VEGF and its receptors. Nat Med 2003, 9:669-676

2. Gille H, Kowalski J, Li B, LeCouter J, Moffat B, Zioncheck TF, Pelletier $\mathrm{N}$, Ferrara N: Analysis of biological effects and signaling properties of Flt-1 (VEGFR-1) and KDR (VEGFR-2). A reassessment using novel receptor-specific vascular endothelial growth factor mutants. J Biol Chem 2001, 276:3222-3230

3. Brown KR, England KM, Goss KL, Snyder JM, Acarregui MJ: VEGF induces airway epithelial cell proliferation in human fetal lung in vitro. Am J Physiol Lung Cell Mol Physiol 2001, 281:L1001-L1010

4. Barleon B, Hauser S, Schollmann C, Weindel K, Marme D, Yayon A Weich HA: Differential expression of the two VEGF receptors flt and KDR in placenta and vascular endothelial cells. J Cell Biochem 1994, 54:56-66

5. Becker PM, Verin AD, Booth MA, Liu F, Birukova A, Garcia JG Differential regulation of diverse physiological responses to VEGF in pulmonary endothelial cells. Am J Physiol Lung Cell Mol Physiol 2001, 281:L1500-L1511

6. Godzich M, Hodnett M, Frank JA, Su G, Pespeni M, Angel A, Howard MB, Matthay MA, Pittet JF: Activation of the stress protein response prevents the development of pulmonary edema by inhibiting VEGF cell signaling in a model of lung ischemia-reperfusion injury in rats. FASEB J 2006, 20:1519-1521

7. Paul R, Zhang ZG, Eliceiri BP, Jiang Q, Boccia AD, Zhang RL, Chopp M, Cheresh DA: Src deficiency or blockade of Src activity in mice provides cerebral protection following stroke. Nat Med 2001, 7:222-227

8. van Bruggen N, Thibodeaux H, Palmer JT, Lee WP, Fu L, Cairns B, Tumas D, Gerlai R, Williams SP, van Lookeren Campagne M, Ferrara $\mathrm{N}$ : VEGF antagonism reduces edema formation and tissue damage after ischemia/reperfusion injury in the mouse brain. J Clin Invest 1999, 104:1613-1620

9. Mura M, dos Santos CC, Stewart D, Liu M: Vascular endothelial growth factor and related molecules in acute lung injury. J Appl Physiol 2004, 97:1605-1617

10. Kaner RJ, Ladetto JV, Singh R, Fukuda N, Matthay MA, Crystal RG: Lung overexpression of the vascular endothelial growth factor gene induces pulmonary edema. Am J Respir Cell Mol Biol 2000, 22:657-664

11. Lee CG, Link H, Baluk P, Homer RJ, Chapoval S, Bhandari V, Kang MJ, Cohn L, Kim YK, McDonald DM, Elias JA: Vascular endothelial growth factor (VEGF) induces remodeling and enhances TH2-mediated sensitization and inflammation in the lung. Nat Med 2004, 10:1095-1103

12. Hamada N, Kuwano K, Yamada M, Hagimoto N, Hiasa K, Egashira K, Nakashima N, Maeyama T, Yoshimi M, Nakanishi Y: Anti-vascular endothelial growth factor gene therapy attenuates lung injury and fibrosis in mice. J Immunol 2005, 175:1224-1231

13. Ware LB, Kaner RJ, Crystal RG, Schane R, Trivedi NN, McAuley D, Matthay MA: VEGF levels in the alveolar compartment do not distinguish between ARDS and hydrostatic pulmonary oedema. Eur Respir J2005, 26:101-105

14. Thickett DR, Armstrong L, Millar AB: A role for vascular endothelial growth factor in acute and resolving lung injury. Am J Respir Crit Care Med 2002, 166:1332-1337

15. Tuder RM, Zhen L, Cho CY, Taraseviciene-Stewart L, Kasahara Y, 
Salvemini D, Voelkel NF, Flores SC: Oxidative stress and apoptosis interact and cause emphysema due to vascular endothelial growth factor receptor blockade. Am J Respir Cell Mol Biol 2003, 29:88-97

16. Tang K, Rossiter HB, Wagner PD, Breen EC: Lung-targeted VEGF inactivation leads to an emphysema phenotype in mice, J Appl Physiol 2004, 97:1559-1566; discussion 1549

17. Kaner RJ, Crystal RG: Compartmentalization of vascular endothelial growth factor to the epithelial surface of the human lung. Mol Med 2001, 7:240-246

18. Corne J, Chupp G, Lee CG, Homer RJ, Zhu Z, Chen Q, Ma B, Du Y, Roux F, McArdle J, Waxman AB, Elias JA: IL-13 stimulates vascular endothelial cell growth factor and protects against hyperoxic acute lung injury. J Clin Invest 2000, 106:783-791

19. Roberts JR, Perkins GD, Fujisawa T, Pettigrew KA, Gao F, Ahmed A, Thickett DR: Vascular endothelial growth factor promotes physical wound repair and is anti-apoptotic in primary distal lung epithelial and A549 cells. Crit Care Med 2007, 35:2164-2170

20. Shifren JL, Doldi N, Ferrara N, Mesiano S, Jaffe RB: In the human fetus, vascular endothelial growth factor is expressed in epithelial cells and myocytes, but not vascular endothelium: implications for mode of action. J Clin Endocrinol Metab 1994, 79:316-322

21. Souza DG, Soares AC, Pinho V, Torloni H, Reis LF, Teixeira MM, Dias AA: Increased mortality and inflammation in tumor necrosis factorstimulated gene-14 transgenic mice after ischemia and reperfusion injury. Am J Pathol 2002, 160:1755-1765

22. Novak A, Guo C, Yang W, Nagy A, Lobe CG: Z/EG, a double reporter mouse line that expresses enhanced green fluorescent protein upon Cre-mediated excision. Genesis 2000, 28:147-155

23. Chalfie M, Tu Y, Euskirchen G, Ward WW, Prasher DC: Green fluorescent protein as a marker for gene expression. Science 1994, 263:802-805

24. Eremina V, Sood M, Haigh J, Nagy A, Lajoie G, Ferrara N, Gerber HP, Kikkawa Y, Miner JH, Quaggin SE: Glomerular-specific alterations of VEGF-A expression lead to distinct congenital and acquired renal diseases. J Clin Invest 2003, 111:707-716

25. dos Santos CC, Han B, Andrade CF, Bai X, Uhlig S, Hubmayr R, Tsang M, Lodyga M, Keshavjee S, Slutsky AS, Liu M: DNA microarray analysis of gene expression in alveolar epithelial cells in response to TNFalpha, LPS, and cyclic stretch. Physiol Genomics 2004, 19:331-342

26. Yao H, Edirisinghe I, Yang SR, Rajendrasozhan S, Kode A, Caito S, Adenuga D, Rahman I: Genetic ablation of NADPH oxidase enhances susceptibility to cigarette smoke-induced lung inflammation and emphysema in mice. Am J Pathol 2008, 172:1222-1237

27. Mura M, Andrade CF, Han B, Seth R, Zhang Y, Bai XH, Waddell TK, Hwang $\mathrm{D}$, Keshavjee $\mathrm{S}$, Liu M: Intestinal ischemia-reperfusion-induced acute lung injury and oncotic cell death in multiple organs. Shock 2007, 28:227-238

28. Mura M, Han B, Andrade CF, Seth R, Hwang D, Waddell TK, Keshavjee S, Liu M: The early responses of VEGF and its receptors during acute lung injury: implication of VEGF in alveolar epithelial cell survival. Crit Care 2006, 10:R130

29. Swaisgood CM, French EL, Noga C, Simon RH, Ploplis VA: The development of bleomycin-induced pulmonary fibrosis in mice deficient for components of the fibrinolytic system. Am J Pathol 2000, 157:177-187

30. Ginsberg HS, Horswood RL, Chanock RM, Prince GA: Role of early genes in pathogenesis of adenovirus pneumonia. Proc Natl Acad Sci USA 1990, 87:6191-6195

31. Han B, Mura M, Andrade CF, Okutani D, Lodyga M, dos Santos CC, Keshavjee S, Matthay M, Liu M: TNFalpha-induced long pentraxin PTX3 expression in human lung epithelial cells via JNK. J Immunol 2005, 175:8303-8311

32. Abadie Y, Bregeon F, Papazian L, Lange F, Chailley-Heu B, Thomas P, Duvaldestin P, Adnot S, Maitre B, Delclaux C: Decreased VEGF concentration in lung tissue and vascular injury during ARDS. Eur Respir J2005, 25:139-146

33. Krajewski S, Zapata JM, Krajewska M, VanArsdale T, Shabaik A, Gascoyne RD, Reed JC: Immunohistochemical analysis of in vivo patterns of TRAF-3 expression, a member of the TNF receptor-associated factor family. J Immunol 1997, 159:5841-5852

34. Tang PS, Mura M, Seth R, Liu M: Acute lung injury and cell death: how many ways can cells die? Am J Physiol Lung Cell Mol Physiol 2008, 294:L632-L641

35. Fehrenbach A, Pufe T, Wittwer T, Nagib R, Dreyer N, Pech T, Petersen
W, Fehrenbach H, Wahlers T, Richter J: Reduced vascular endothelial growth factor correlates with alveolar epithelial damage after experimental ischemia and reperfusion. J Heart Lung Transplant 2003, 22:967-978

36. Kazi AA, Lee WS, Wagner E, Becker PM: VEGF, fetal liver kinase-1, and permeability increase during unilateral lung ischemia. Am J Physiol Lung Cell Mol Physiol 2000, 279:L460-L467

37. Maitre B, Boussat S, Jean D, Gouge M, Brochard L, Housset B, Adnot S, Delclaux C: Vascular endothelial growth factor synthesis in the acute phase of experimental and clinical lung injury. Eur Respir $J$ 2001, 18:100-106

38. Thickett DR, Armstrong L, Christie SJ, Millar AB: Vascular endothelial growth factor may contribute to increased vascular permeability in acute respiratory distress syndrome. Am J Respir Crit Care Med 2001, 164:1601-1605

39. Pham I, Uchida T, Planes C, Ware LB, Kaner R, Matthay MA, Clerici C: Hypoxia upregulates VEGF expression in alveolar epithelial cells in vitro and in vivo. Am J Physiol Lung Cell Mol Physiol 2002, 283:L1133-L1142

40. Fehrenbach H, Kasper M, Haase M, Schuh D, Muller M: Differential immunolocalization of VEGF in rat and human adult lung, and in experimental rat lung fibrosis: light, fluorescence, and electron microscopy. Anat Rec 1999, 254:61-73

41. Tuder RM, Flook BE, Voelkel NF: Increased gene expression for VEGF and the VEGF receptors KDR/Flk and Flt in lungs exposed to acute or to chronic hypoxia. Modulation of gene expression by nitric oxide. J Clin Invest 1995, 95:1798-1807

42. Ferrara N, Carver-Moore K, Chen H, Dowd M, Lu L, O'Shea KS, Powell-Braxton L, Hillan KJ, Moore MW: Heterozygous embryonic lethality induced by targeted inactivation of the VEGF gene. Nature 1996, 380:439-442

43. Yamamoto H, Yun EJ, Gerber HP, Ferrara N, Whitsett JA, Vu TH: Epithelial-vascular cross talk mediated by VEGF-A and HGF signaling directs primary septae formation during distal lung morphogenesis. Dev Biol 2007, 308:44-53

44. Kasahara Y, Tuder RM, Taraseviciene-Stewart L, Le Cras TD, Abman S, Hirth PK, Waltenberger J, Voelkel NF: Inhibition of VEGF receptors causes lung cell apoptosis and emphysema. J Clin Invest 2000, 106:1311-1319

45. Bhandari V, Choo-Wing R, Chapoval SP, Lee CG, Tang C, Kim YK, Ma B, Baluk P, Lin MI, McDonald DM, Homer RJ, Sessa WC, Elias JA: Essential role of nitric oxide in VEGF-induced, asthma-like angiogenic, inflammatory, mucus, and physiologic responses in the lung. Proc Natl Acad Sci USA 2006, 103:11021-11026

46. Le Cras TD, Spitzmiller RE, Albertine KH, Greenberg JM, Whitsett JA, Akeson AL: VEGF causes pulmonary hemorrhage, hemosiderosis, and air space enlargement in neonatal mice. Am J Physiol Lung Cell Mol Physiol 2004, 287:L134-L142

47. Lee CG, Yoon HJ, Zhu Z, Link H, Wang Z, Gwaltney JM, Landry M, Elias JA: Respiratory syncytial virus stimulation of vascular endothelial cell growth factor/vascular permeability factor. Am J Respir Cell Mol Biol 2000, 23:662-669

48. Becker PM, Alcasabas A, Yu AY, Semenza GL, Bunton TE: Oxygenindependent upregulation of vascular endothelial growth factor and vascular barrier dysfunction during ventilated pulmonary ischemia in isolated ferret lungs. Am J Respir Cell Mol Biol 2000, 22:272-279

49. Gerber HP, McMurtrey A, Kowalski J, Yan M, Keyt BA, Dixit V, Ferrara $\mathrm{N}$ : Vascular endothelial growth factor regulates endothelial cell survival through the phosphatidylinositol 3'-kinase/Akt signal transduction pathway. Requirement for Flk-1/KDR activation. J Biol Chem 1998, 273:30336-30343

50. Albertine KH, Plopper CG: DNA oxidation or apoptosis: will the real culprit of dna damage in hyperoxic lung injury please stand up? Am J Respir Cell Mol Biol 2002, 26:381-383

51. Wang X, Ryter SW, Dai C, Tang ZL, Watkins SC, Yin XM, Song R, Choi AM: Necrotic cell death in response to oxidant stress involves the activation of the apoptogenic caspase-8/bid pathway. J Biol Chem 2003, 278:29184-29191

52. Bhandari V, Choo-Wing R, Lee CG, Zhu Z, Nedrelow JH, Chupp GL, Zhang X, Matthay MA, Ware LB, Homer RJ, Lee PJ, Geick A, de Fougerolles AR, Elias JA: Hyperoxia causes angiopoietin 2-mediated acute lung injury and necrotic cell death. Nat Med 2006, 12:1286-1293 